\title{
SWMF simulation of field-aligned currents for a varying northward and duskward IMF with nonzero dipole tilt
}

\author{
H. Wang ${ }^{1, *}$, A. J. Ridley ${ }^{1}$, and H. Lühr ${ }^{2}$ \\ ${ }^{1}$ Department of Atmospheric, Oceanic, and Space Sciences, University of Michigan, Ann Arbor, MI-48109, USA \\ ${ }^{2}$ GeoForshungsZentrum Potsdam, 14473 Potsdam, Germany \\ *On leave from College of Electronic Informatics, Wuhan University, Wuhan 430079, P. R. China
}

Received: 22 January 2008 - Revised: 27 March 2008 - Accepted: 16 April 2008 - Published: 11 June 2008

\begin{abstract}
This study concentrates on the FACs distribution for the varying northward and duskward interplanetary magnetic field (IMF) conditions when the dipole tilt is nonzero. A global MHD simulation (the Space Weather Modeling Framework, SWMF) has been used to perform this study. Hemispheric asymmetry of the time evolution of northward IMF $B_{z}$ (NBZ) FACs is found. As the IMF changes from strictly northward to duskward, NBZ FACs shift counterclockwise in both summer and winter hemispheres. However, in the winter hemisphere, the counterclockwise rotation prohibits the duskward NBZ FACs from evolving into the midday R1 FACs. The midday R1 FACs seem to be an intrusion of dawnside R1 FACs. In the summer hemisphere, the NBZ FACs can evolve into the DPY FACs, consisting of the midday R0 and R1 FACs, after the counterclockwise rotation. The hemispheric asymmetry is due to the fact that the dipole tilt favors more reconnection between the IMF and the summer magnetosphere. When mapping the NBZ and DPY FACs into the magnetosphere it is found that the NBZ currents are located on both open and closed field lines, irrespective of the IMF direction. For the DPY FACs the hemispheric asymmetry emerges: the midday R1 FACs and a small part of R0 FACs are on closed field lines in the winter hemisphere, while a small part of the midday R1 FACs and all the R0 FACs are on open field lines in the summer hemisphere. Both IMF $B_{y}$ and dipole tilt cause the polar cap hemispheric and local time asymmetric. When the IMF is northward, the summer polar cap is closed on the nightside while the winter polar cap is open. The polar cap boundary tends to move equatorward as the IMF rotates from northward to duskward, except in the summer hemisphere, the polar cap on the dawnside shifts poleward when the clock angle is less than $10^{\circ}$. The further poleward displacement of the polar cap boundary on one oval side is caused by the
\end{abstract}

Correspondence to: H. Wang

(whui@umich.edu) twist of the tail plasma sheet, which is in accordance with the changing open field lines topology in the magnetotail.

Keywords. Ionosphere (Ionosphere-magnetosphere interactions; Electric fields and currents; Modeling and forecasting)

\section{Introduction}

When the interplanterary magnetic field (IMF) is northward, some interesting phenomena will occur at the high latitude ionosphere, like the theta aurora (Frank et al., 1982), sunward convection (Burke et al., 1979), and northward IMF $B_{z}$ (NBZ) field-aligned currents (FACs) (Iijima et al., 1984). The magnetic merging between the northward IMF and the Earth's magnetic fields at the high latitude is believed to be associated with these ionospheric phenomena (e.g. Dungey, 1963; Clauer and Friis-Christensen, 1988; Fedder and Lyon, 1995; Øieroset et al., 1997). Many studies have investigated the effects of IMF $B_{y}, B_{x}$ and the Earth's dipole tilt on the dawn-dusk hemispheric asymmetries of the antiparallel reconnection topologies (e.g. Crooker et al., 1985; Lyons, 1985; Crooker, 1992; Feldman et al., 1995; Lockwood and Moen, 1999) and the associated ionospheric signatures (e.g. Ogino et al., 1985; Reiff and Burch, 1985; Yamauchi et al., 1993; Taguchi et al., 1994; Crooker et al., 1998; Tanaka, 1999; Le et al., 2002; Østgaard et al., 2003; Vennerstrom et al., 2005; Park et al., 2006).

FACs play an important role in the processes of the electromagnetic energy coupling between the solar wind, magnetosphere, and ionosphere. Previous studies have revealed several types of FACs (e.g. Iijima and Potemra, 1976; Iijima et al., 1984). The NBZ FACs dominate in the polar cap poleward of the Region 1 (R1) current region with an opposite sense of flow direction to R1 (Iijima et al., 1984). A cartoon of the typical distribution of NBZ and R1 FACs is shown in Fig. 1. In the Northern Hemisphere, when IMF

Published by Copernicus Publications on behalf of the European Geosciences Union. 


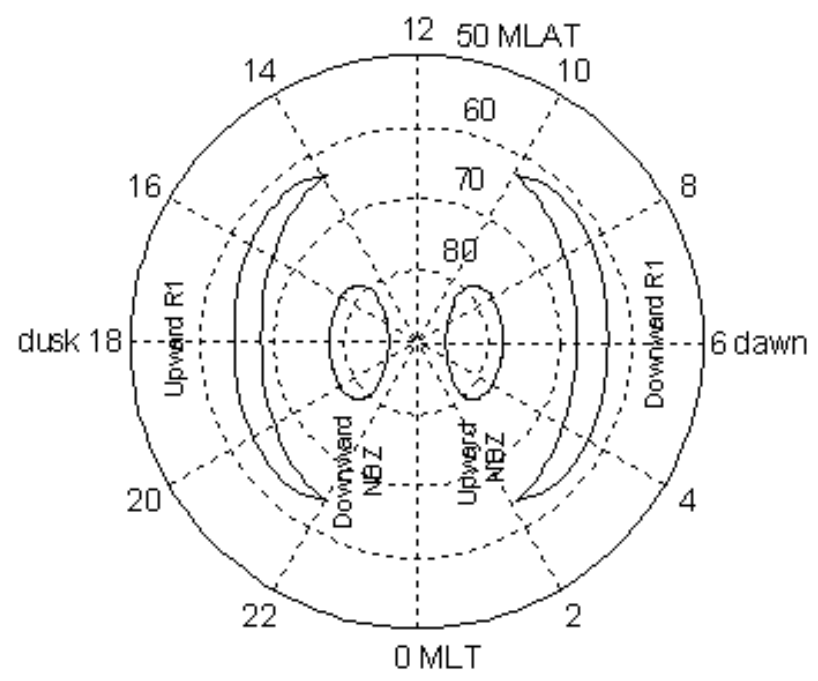

Fig. 1. Cartoon of the typical distribution of the NBZ and R1 FACs for positive IMF $B_{z}$.

$B_{y}>0(<0)$ the duskside (dawnside) NBZ FACs are confined to a smaller region compared to the dawnside (duskside), and vice versa in the Southern Hemisphere (Iijima and Shibaji, 1987). When IMF $B_{y}$ is dominant, a pair of oppositely directed oval-aligned FACs are observed in the noon sector (e.g. Iijima and Potemra, 1976; Wilhjelm et al., 1978), termed DPY FACs in the literature (Clauer and Friis-Christensen, 1988). In the Northern Hemisphere, when $B_{y}>0(<0)$, the DPY FACs consist of currents flowing into (away from) the ionosphere at the poleward part and away from (into) the ionosphere at the equatorward part. The more poleward part of the DPY FAC is termed "cusp", "mantel", or "R0" current due to the different interpretation of source regions and mechanisms (Iijima and Potemra, 1976, 1982; Erlandson et al., 1988). We denote the poleward part of the DPY FACs as midday R0 and the equatorward part as midday R1 FACs in this study.

Despite the vast efforts of previous studies, the magnetospheric origins and the detailed configurations of NBZ and DPY FACs, as well as their inherent relationship, are still not clearly understood. The NBZ FACs have been interpreted in terms of the antiparallel reconnection on field lines tailward of the dayside cusp, which are located on open field lines (Crooker, 1988). However, Vennerstrom et al. (2005) found that the NBZ FACs and the dayside R1 FACs can be generated on both open and closed field lines based on a model simulation. Different points of view have also been proposed concerning the DPY FACs. McDiarmid et al. (1979) presented a picture that the midday R1 currents correspond to R1 currents that are extended from the dawn $\left(B_{y}>0\right)$ and dusk $\left(B_{y}<0\right)$ hours, presumably on closed geomagnetic field lines in the Northern Hemisphere. These results were obtained by using the magnetic field and particle data from the ISIS 2 satellite. They speculated that the midday R1 current is ac- companied by magnetosheath-like cleft particles suggesting an ionospheric mapping of the low-latitude boundary layer (LLBL) (Potemra et al., 1987). This point of view was supported by Friis-Christensen et al. (1985) by using ground based magnetometer observations. Erlandson et al. (1988), using simultaneous particle and magnetic field data acquired with the Viking satellite, suggested that a portion of the midday R1 FACs is mapped to the entry layer and is associated with the cleft particle precipitation. Whereas the midday R0 FACs is mapped to the plasma mantle and is associated with plasma mantle precipitation. As a unified picture of the R1 current, they also suggested that the equatorward current sheet is an extension of the dawnside or duskside R1 current across noon, depending on the IMF $B_{y}$ polarity. These studies (e.g. McDiarmid et al., 1979; Friis-Christensen et al., 1985; Erlandson et al., 1988) all concluded that the midday $\mathrm{R} 1$ current is an intrusion of dawnside or duskside R1 currents. In summary, the midday R1 current is mostly, but not entirely, located on closed magnetic field lines, while the midday R0 FACs is on open magnetic field lines.

However, Taguchi et al. (1993), using the magnetic field and electron data from DE 2 satellite, advocated a model that both midday R1 and R0 FACs reside on open geomagnetic field lines and can be discriminated from the R1/R2 current system in the morning and evening sector that are located mostly on closed geomagnetic field lines. Mei et al. (1994) developed a self-consistent cusp current model from ionospheric sources according to Ohm's law, by mapping the solar wind electric field to only a limited area of the polar cap around the cusp. They showed that the cusp FACs originate from the poleward edges of cusp/cleft regions in the northern and southern magnetosphere and are located on open field lines. Yamauchi et al. (1993) proposed nearly the same idea as that by Taguchi et al. (1993) except that the source of the closed magnetic field line region also contributes to the midday R1 FACs. From the imbalance of current intensities between midday R0 and R1 FACs, there is an excess of R0 FACs intensity over that of midday R1 FACs for many cases, Watanabe et al. (1996) found by using DMSP particle and magnetic field data that the midday R1 consists of two distinctive parts: one associated with the cusp/mantle region, presumably on open magnetic field lines, and the other associated with the cleft/outer plasma sheet. Thus, there remains some conflicts over the source region of the midday R1 and R0 FACs. One of the main purpose of this paper is to provide an integrated picture of the FAC system when the IMF changes from northward to duskward, thereby attempting to clarify the magnetospheric sources of NBZ and DPY FACs.

In contrast to the accepted classification scheme of NBZ and DPY FACs as distinct systems, some studies suggested that the two DPY FACs can rotate to form the two NBZ FACs as the IMF rotates from dawnward to strongly northward, which was demonstrated by Fedder et al. (1997) with both a global numerical simulation and satellite (Polar) observations. Vennerstrom et al. (2002) and Vennerstrom et al. 
(2005) also found that NBZ FACs can evolve into DPY, as the IMF rotates from northward to duskward, based on Ørsted magnetic field observations and open GGCM (Global Geospace Coupling Model) simulations. These studies argued that the major physical differences between the NBZ and DPY current systems are the magnetic geometry created by the merging process as IMF rotates about the GSM X axis (Fedder et al., 1997). It is interesting to note that these conclusions were all drawn from event studies at equinox when the Earth's dipole tilt is nearly zero. These authors suggested that examinations of the effects caused by a dipole tilt are necessary. When a nonzero dipole tilt is considered, the hemispheric symmetry is broken, and reconnection will not occur simultaneously and symmetrically at the northern and southern lobes (Crooker, 1992). The magnetic geometry will be greatly altered, which is expected to affect the FACs distribution patterns.

Compared to spatially limited satellite and ground observations, MHD simulations have the advantage that the whole magnetosphere-ionosphere system can be described simultaneously and self-consistently. Using the Space Weather Modeling Framework (SWMF) magnetohydrodynamic (MHD) model developed by the University of Michigan's Center for Space Environment Modeling (CSEM), this work investigates the evolution of FAC systems in both ionosphere and magnetosphere when IMF $B_{z}$ is rotated slowly from northward to duskward. This model study differs from previous work (e.g. Vennerstrom et al., 2005) mainly in that we include the effect of nonzero dipole tilt. When the dipole is tilted and IMF $B_{y}$ and $B_{z}$ components are all nonzero, the magnetosphere is totally asymmetric so that the entire magnetosphere has to be modelled and treated in threedimensions.

The SWMF model will not be detailed here since it is fully described elsewhere (e.g. Tóth et al., 2005). The SWMF has the ability to couple numerical domain models flexibly and efficiently, including models of the solar corona, the heliosphere, the magnetosphere, ionosphere and thermosphere. This framework enables simulations that were not possible with the individual physics models and it is possible to run it in almost real time on large computer systems. The SWMF used in this work includes the BATSRUS model to simulate the magnetosphere of the Earth (Powell et al., 1999), RCM to simulate the Inner Magnetosphere domain (Toffoletto et al., 2003), and the model by Ridley et al. (2004) to describe the ionospheric electrodynamics. Various papers have described these separate domain models and the results of the coupled simulations that can be achieved utilizing these models (e.g. De Zeeuw et al., 2004; Tóth et al., 2007; Wang et al., 2008a). By comparing the SWMF with CHAMP magnetic field observations, it is found that the SWMF can reproduce the structure of FACs rather well (Wang et al., 2008b).

\section{Model results}

The input solar wind and IMF paramters at the upstream boundary of the code $(+32 \mathrm{Re})$ are as following: the solar wind velocity $\left(v_{x s w}\right)$ is $-400 \mathrm{~km} / \mathrm{s}$, the number density $(n)$ is $7 \mathrm{~cm}^{-3}$. At the beginning of the run $B_{z}=10 \mathrm{nT}$, and $B_{y}=0 \mathrm{nT}$. $B_{z}$ and $B_{y}$ are then linearly changed to 0 and $10 \mathrm{nT}$, respectively, in two hours. The IMF $B_{x}$ is kept at zero throughout the run and all the other parameters are kept unchanged. Instead of zero dipole tilt angle, we make the dipole tilt angle in the Northern Hemisphere $30^{\circ}$ tilted away from the sun (i.e. north winter). The Earth is hold steady and the dipole does not rotate during the time of run. The dipole tilt angle is defined as the angle between the Earth's northern dipole axis and the GSM Z axis. The simulation is initiated with 100 min of strictly northward IMF. Then the start time of the simulation after the initiation run is refered to as UT (universal time $)=0$.

\subsection{Ionospheric reconfiguration time}

For the determination of the time delay from the upstream boundary to the magnetosphere and ionopshere, Fig. 2 shows the time evolution of the IMF clock angle, defined as $\arctan \left(B_{y} / B_{z}\right)$, at the upstream boundary and magnetopause, as well as the cross polar cap potential (CPCP) in both hemispheres. From the left figure, it can be seen there is about 10 min time delay from the upstream boundary $\left(32 R_{E}\right)$ to the magnetopause. In the Northern Hemisphere there are no changes that can be seen in the CPCP distributions in the first $20 \mathrm{~min}$, thus, there is about $10 \mathrm{~min}$ time delay can be considered for the propagation of changes from the magnetopause to the ionosphere. In the Southern Hemisphere, there is a small reduction of the CPCP at 00:15 UT, then followed by a gradual enhancement at 00:30 UT, suggesting that the response time in the Southern Hemisphere is 5 min earlier than that in the Northern Hemisphere, but the reconfiguration time is 10 min later than in the Northern Hemisphere. The cause of this initial reduction in the Southern Hemisphere is unclear. In general, we conclude the time delay from the magnetopause for the development of the ionosphere is about 10$20 \mathrm{~min}$.

\subsection{FACs in the ionosphere}

\subsubsection{Morphology of FACs}

The evolution of ionospheric FACs in the frame of magnetic latitude (MLat) and magnetic local time (MLT) as the IMF slowly rotates from northward toward duskward is shown in Figs. 3 (Northern Hemisphere) and 4 (Southern Hemisphere). The times UT, is shown on the upper left of each polar plot from 00:10 UT to 03:00 UT in 10-min increments. Upward currents are yellow and orange and downward are blue. The maximum and minimum values of FAC densities are shown at the bottom of each polar plot. The locations of 

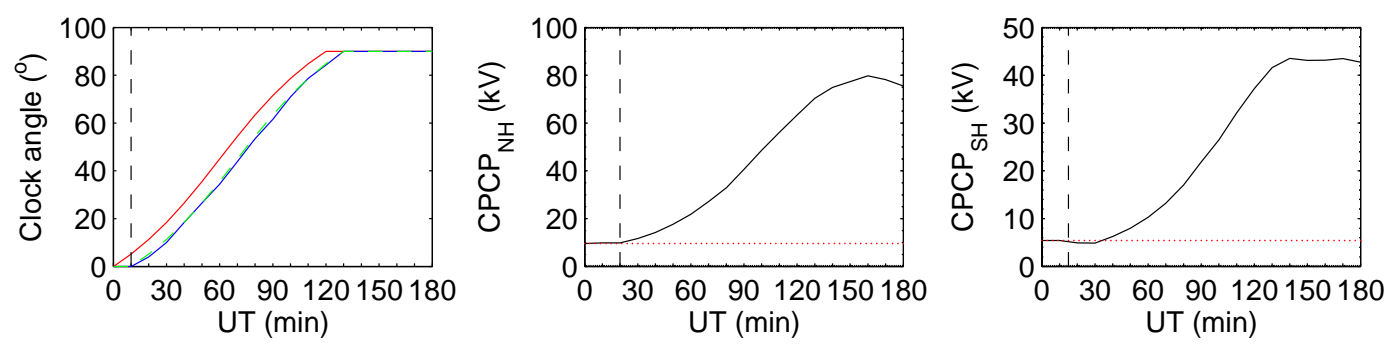

Fig. 2. The left column shows the time evolution of the clock angle defined as $\operatorname{atan}\left(B_{y} / B_{z}\right)$. Red line denotes the IMF clock angle at the $32 R_{E}$, blue denotes the IMF clock angle arriving at the magnetopause, green denotes that of the red line delayed by 10 min. The middle and right columns show the time evolution of the cross polar cap potential in the Northern and Southern Hemispheres. The vertical dashed line indicates 20 (15) min after 00:00 UT in the Northern (Southern) Hemisphere.

the open-closed field boundary derived for eight MLT meridians are shown as asterisks, which will be discussed in the next section.

In Fig. 3, when the IMF is strictly northward, a four cell FAC pattern is observed at high latitude. The NBZ FACs are upward on the dawnside and downward on the duskside, while the R1 FACs are downward on the dawnside and upward on the duskside. As the IMF slowly rotates, the dawnside R1 and NBZ FACs gradually increase in both intensity and size, while the duskside NBZ FACs and R1 current decrease in both intensity and size.

As the IMF rotates toward duskward (e.g. the clock angle changes from $0^{\circ}$ to $90^{\circ}$ ), the former dawnside NBZ FACs shift counterclockwise. Around 01:30 UT, the dawnside NBZ FACs have evolved into an upward midday R0 current centering around noon, while the dawnside R1 FACs have extended into the noon region to form the midday R1 FACs. After that, the upward NBZ FACs continuously and smoothly expand towards the dusk and become indistinguishable from the duskside R1 FACs. The upward NBZ FACs dominate most of the polar cap on the dayside. The duskside NBZ FACs gradually shift counterclockwise along the longitudinal meridian towards midnight. Around 01:10 UT, the duskside NBZ currents merge with the dawnside R1 FACs. From the above analysis it can be seen that it is not the duskside NBZ FACs, but the dawnside R1 FACs that become the midday R1 FACs, contradicting previous results (e.g. Vennerstrom et al., 2005). Around 01:10-01:20 UT, a weak downward current sheet appears on the duskside. From the flow direction it can be identified as the R2 FACs. These R2 FACs are associated with the enhancement of plasma pressure, which will be discussed in Sect. 3.3. As the IMF $B_{y}$ intensifies, the R2 FACs intensify and expand in longitude with the center shift towards the premidnight. At 02:50 UT a weak R2 upward FACs also appears in the early morning sector.

When examining the FACs in the Southern Hemisphere there are several differences from the pattern in the Northern Hemisphere: (1) the duskside R1 and NBZ currents strengthen and expand in size while the dawnside R1 and
NBZ currents shrink and diminish, which is a mirror image of the Northern Hemisphere with respect to the noonmidnight meridian; (2) the former duskside NBZ FACs rotate counterclockwise across midnight toward dawn and merge with the dawnside R1 FAC. This downward NBZ FACs dominate most of the polar cap on the nightside. It is interesting that the dawnside R1 FACs split into two parts, with one extending into midnight to merge with the duskside NBZ FACs and the other remains at the same place. Around 01:20 UT, this residual FAC also merges with the duskside NBZ FACs; (3) the former dawnside NBZ FACs rotate counterclockwise across the noon towards dusk and eventually become indistinguishable from the duskside R1 FACs around 00:50 UT. Thus, the two NBZ FACs rotate to form the two DPY FACs, which is consistent with previous results (e.g. Vennerstrom et al., 2005). Similar to the Northern Hemisphere, R2 FACs appear at the more equatorward latitudes when IMF varies from purely northward to duskward.

\subsubsection{The variation of FACs with the clock angle}

It seems that FACs densities are strongly sensitive to changes in the clock angle. Figure 5 shows the variation of the peak densities of the dominant NBZ and R1 FACs on the dawnside (duskside) in the Northern (Southern) Hemisphere as a function of the IMF clock angle, which has been 10 (20) min time delayed from the magnetopause to the ionosphere. The NBZ and R1 FACs on the duskside (dawnside) in the Northern (Southern) Hemisphere are not shown because they decrease in intensity, merge with the dominant R1 and NBZ FACs and become indistinguishable.

Both NBZ and R1 FACs densities are enhanced as the clock angle increases. In the Northern (Southern) Hemisphere the peak densities of the NBZ FACs under duskward IMF (clock angle $=90^{\circ}$ ) are about $3.5(4)$ times larger than those under northward IMF (clock angle $=0^{\circ}$ ). The ratio of the FAC densities between summer and winter (i.e. south and north) is shown in the right panel of Fig. 5. The summer/winter (i.e. south/north) ratio for NBZ FACs is 1.5 1.8, which is larger than that $(1 \sim 1.5)$ for R1 FACs. 

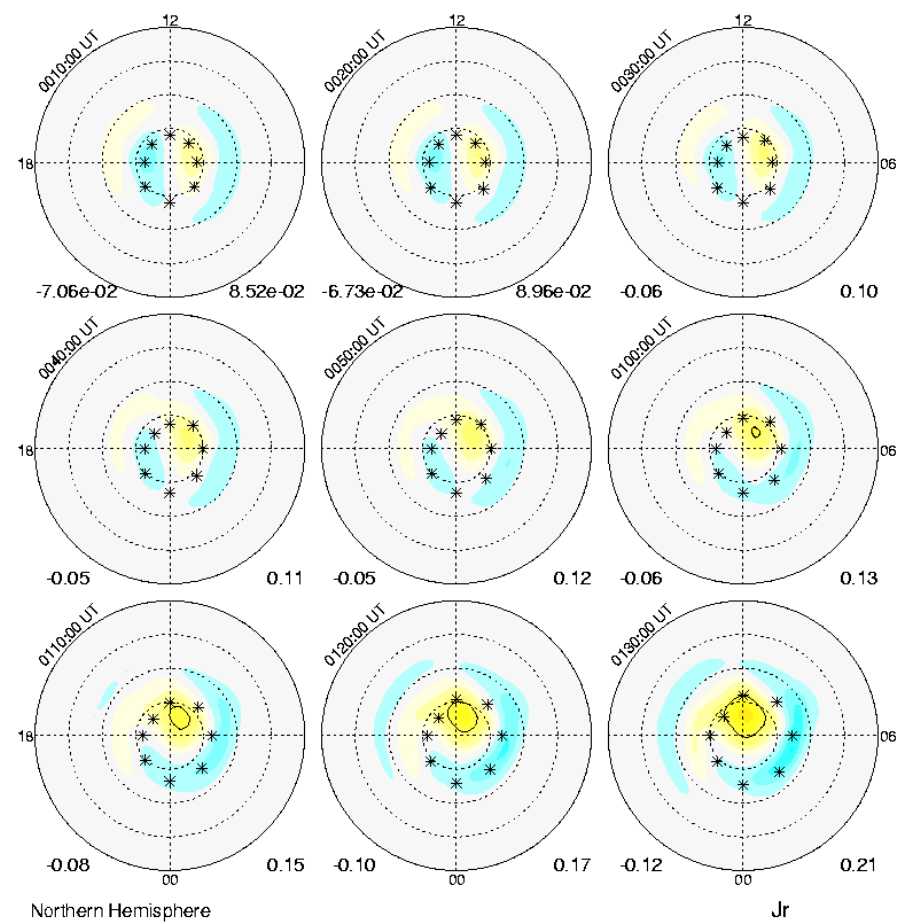

Northern Hemisphere
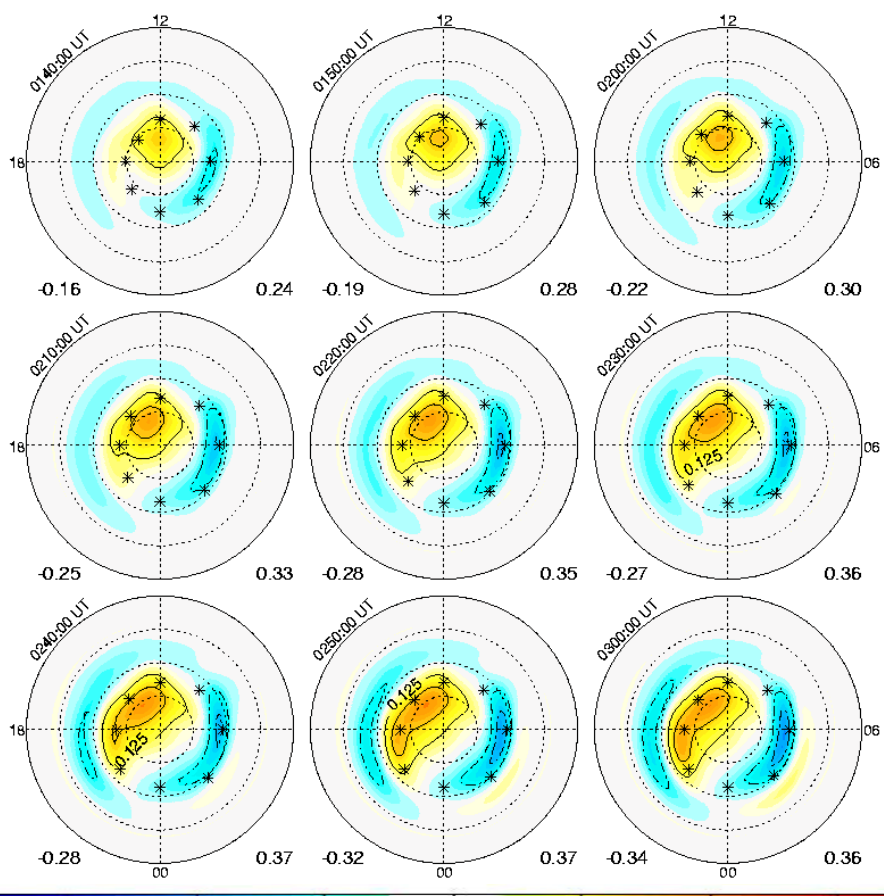

4

$-0.3$

$-0.2$

-0.1

0.2

0.3

Fig. 3. Field-aligned currents $\left(\mu \mathrm{A} / \mathrm{m}^{2}\right)$ in the Northern (i.e. winter) Hemisphere under varying northward and duskward IMF. The color coding shows the field-aligned current densities and the contours indicates the equal current density. The asterisks mark the open/closed field line boundary. 

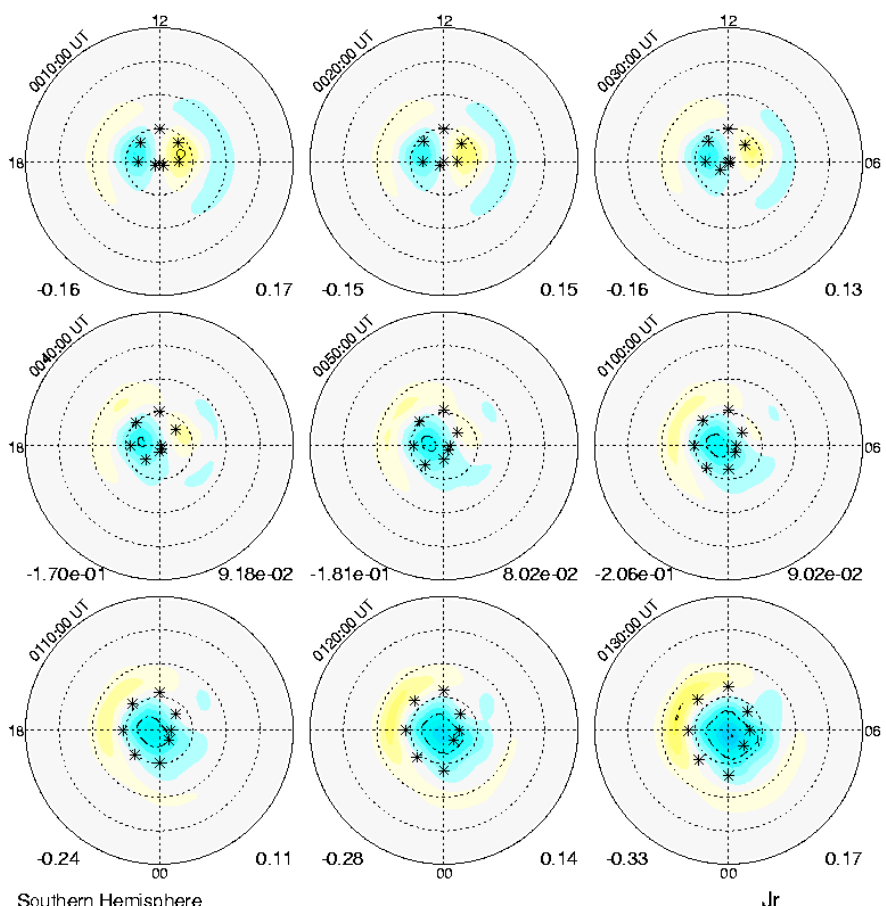

Southern Hemisphere
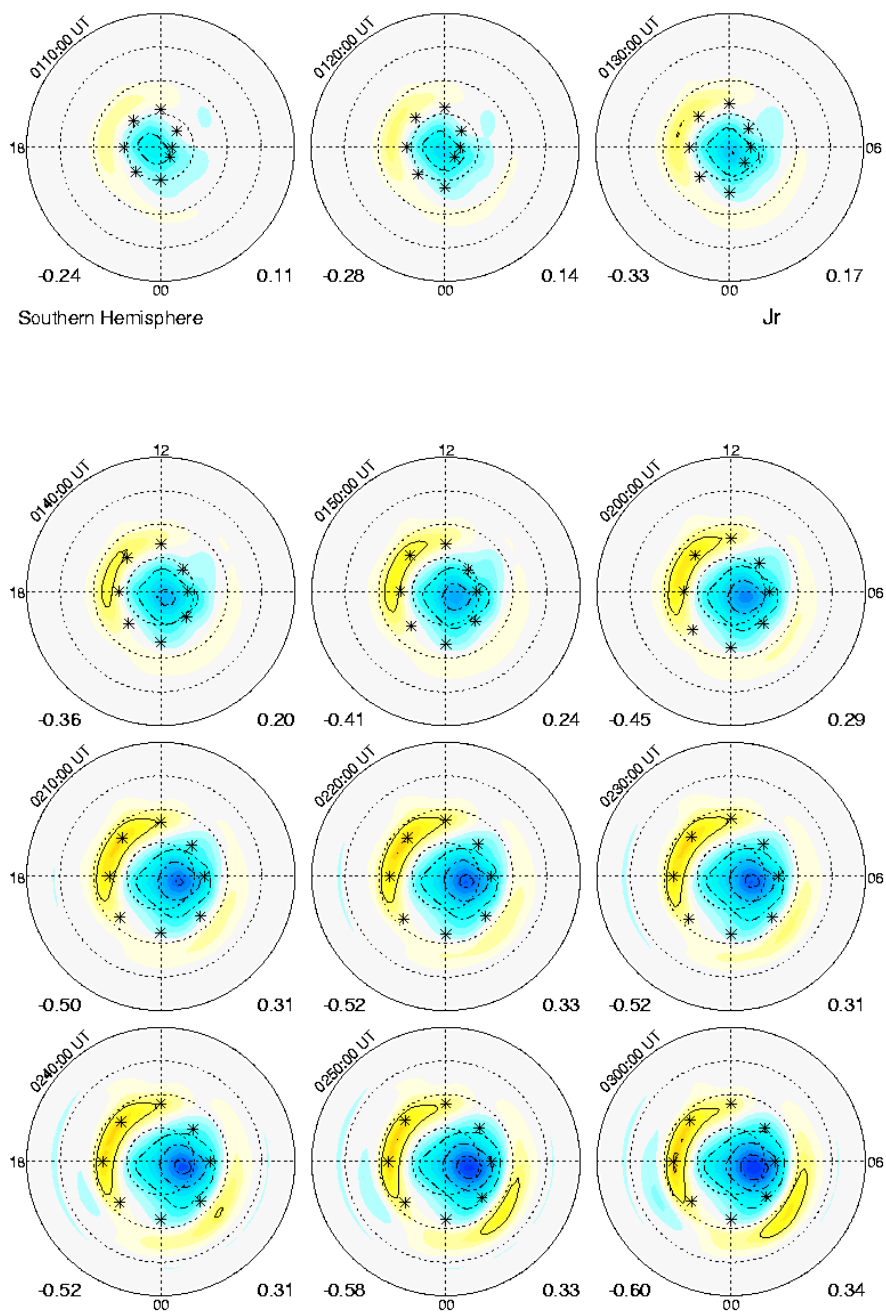

$-0.5$

$-0.4$
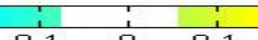

012

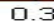

0.4

Fig. 4. Field-aligned currents $\left(\mu \mathrm{A} / \mathrm{m}^{2}\right)$ in the Southern (i.e. summer) Hemisphere under varying northward and duskward IMF. The color coding shows the field-aligned current densities and the contours indicate equal current density. The asterisks mark the open/closed field line boundary. 

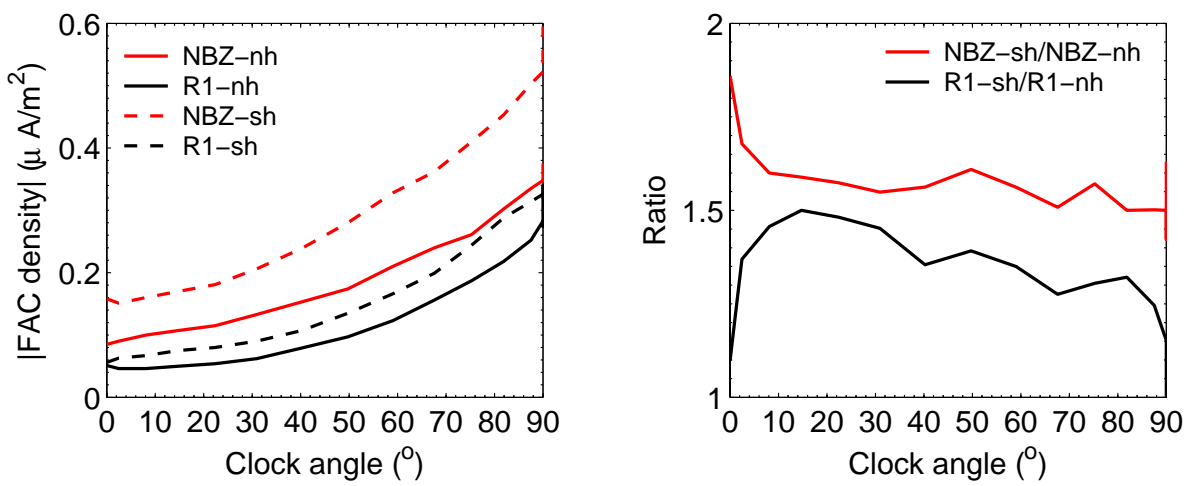

Fig. 5. Left is the peak density of the dominant NBZ and R1 FACs in both hemispheres as a function of the clock angle which has been time shifted from the upperstream boundary to the ionosphere. The solid lines denote the Northern Hemisphere and the dashed lines the Southern Hemisphere. Red is for NBZ FACs and black is for R1 FACs. Right are the ratios between FACs densities in the Southern Hemisphere and those in the Northern Hemisphere (summer/winter).

The MLT and MLat positions where the the dominant NBZ and R1 FACs peak in density are shown in Fig. 6. As the IMF varies, the center of the winter (i.e. north) NBZ FACs rotates across noon from 06:00 MLT to 15:00 MLT with the MLat fluctuate a little around $83^{\circ}$ MLat. The center of summer (i.e. south) NBZ FACs shifts across midnight from 16:00 MLT to 05:00 MLT and moves firstly poleward to $\sim 88^{\circ}$ MLat then equatorward to $82^{\circ}$ MLat. The summer NBZ FACs are centered at relatively higher latitudes than the winter NBZ FACs during most of the period with the largest displacement of $4^{\circ}$ in MLat when the clock angle $=55^{\circ}$ and both NBZ FACs are centered around noon. Different from NBZ FACs, the peak R1 FACs in both hemispheres do not change significantly in locations. They remain on the dawnside (duskside) at $\sim \pm 73^{\circ}$ MLat in both hemispheres.

\subsection{Polar cap boundary}

In order to determine whether the NBZ and DPY FACs originate on open or closed field-lines, the field lines between $60^{\circ}$ and $90^{\circ}$ MLat are mapped in $1^{\circ}$ by $4 \mathrm{~h}$ bins from the ionosphere to the magnetosphere. The first open field line (i.e. does not map to the opposite hemisphere) is recorded. The locations of the open-close field boundary derived for the mapping in both hemispheres are marked by asterisks in Figs. 3 and 4. At the beginning (i.e. under the northward IMF condition) it is interesting to note that the Sorthern Hemisphere has a closed polar cap on the nightside while the north polar cap is open in that local time sector. As the IMF rotates, both polar caps grow in size, with the northern polar cap displacing towards the dawnside and the southern polar cap moving towards the duskside, exhibiting a local time and hemispheric asymmetry. The NBZ FACs are found to be located on both open and closed field lines. The midday R1 FACs and a small part of R0 FACs are on closed field lines in the Northern Hemisphere (i.e. winter), while a small part of the midday R1 FACs and all the R0 FACs are on open field lines in the Southern Hemisphere (i.e. summer).

The polar cap boundary is also sensitive to the changes in the IMF clock angle. The upper row of Fig. 7 shows the latitudes of polar cap boundary in the noon, midnight, dawn, and dusk sectors in both hemispheres as a function of the clock angle. The boundaries move equatorward in all four MLT sectors, as IMF rotates from northward to duskward (i.e. the clock angle increases), except at the dawnside in the Southern Hemisphere, there is a poleward shift of the polar cap when the clock angle $<10^{\circ}$.

At the bottom of Fig. 7 the left panel shows the dawndusk and noon-midnight differences of the latitudinal position of the polar cap boundary separately for the Northern and Southern Hemispheres. If the open closed field line boundary is at a lower latitude at dawn than at dusk, the difference in latitude is then negative. In the north the oval boundary is displaced towards higher latitudes in the noon and dusk sectors, while in the south the polar cap is displaced towards higher latitudes in the midnight and dawn sectors. It is interesting to notice that when the IMF $B_{z}$ is purely northward, the noon-midnight asymmetry surmounts the dawn-dusk asymmetry, which is more obvious in the summer (i.e. southern) hemisphere. But as IMF $B_{y}$ increases in intensity, the dawn-dusk asymmetry increases while the noon-midnight asymmetry decreases. Further, the changes proceed more rapid in the summer (southern) than in the winter (northern) hemisphere.

The right panel at the bottom of Fig. 7 shows the hemispheric (south-north) asymmetries of the polar cap boundary in the noon, midnight, dawn, and dusk meridians. In general, the hemispheric latitudinal displacement is enhanced on both the dawn and dusk sectors. It keeps almost unchanged in the noon sector with the winter polar cap boundary $2^{\circ}$ further poleward of the summer polar cap. The hemispheric latitudinal displacement decreases dramatically in the midnight 

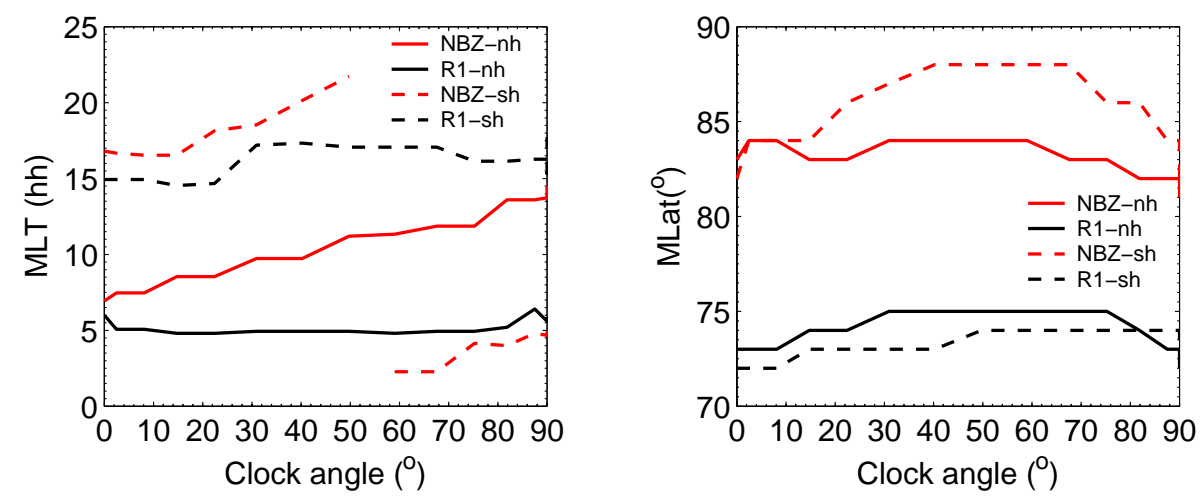

Fig. 6. Variation of the location of the peak FAC densities with the changing clock angle. The solid lines denote the Northern Hemisphere variations and the dashed lines those of the Southern Hemisphere. Red is used for NBZ FACs and black for R1 FACs. Left is the local time evolution of the peak NBZ and R1 FACs in both hemispheres. Right is the MLat evolution of the peak NBZ and R1 FACs.
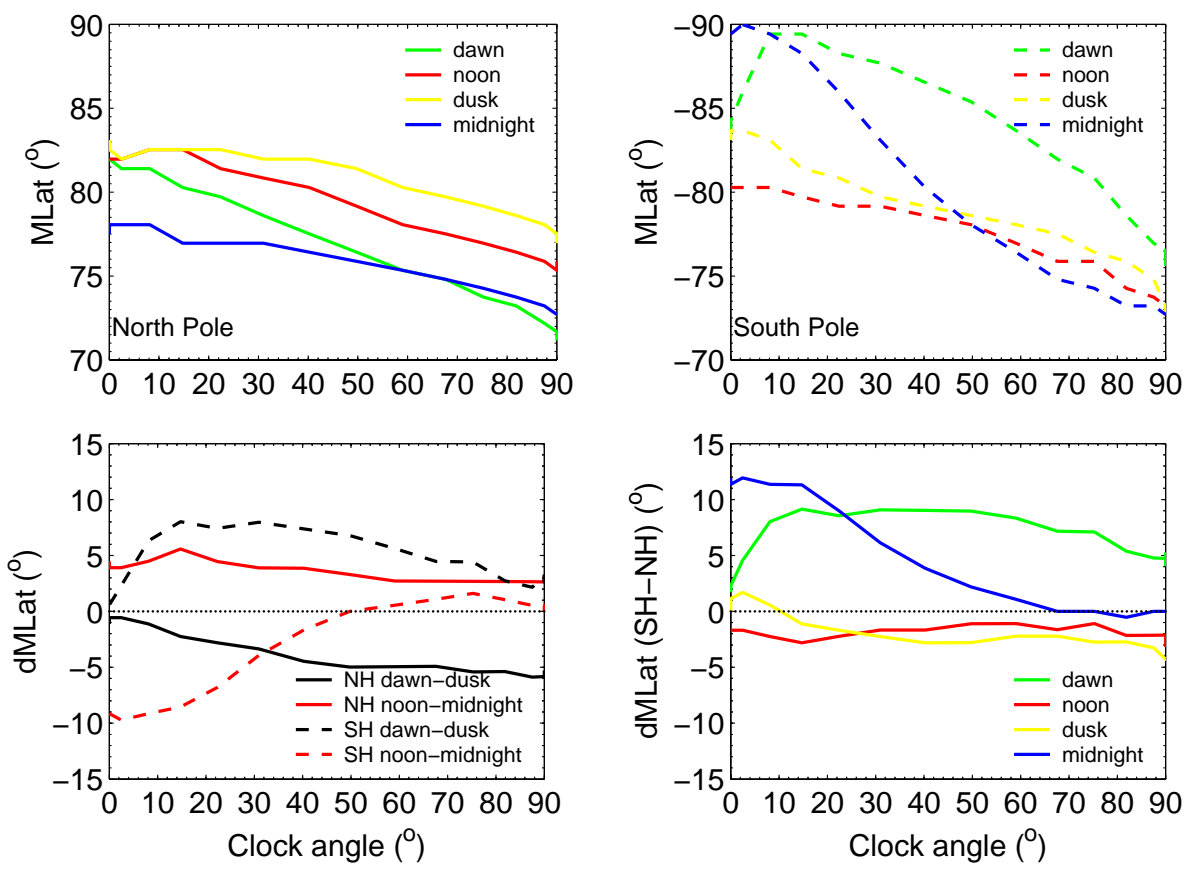

Fig. 7. Shift of the polar cap boundary with the changing clock angle. The top two panels show the time evolution of the open-close field line boundary in the noon, midnight, dawn, and dusk sectors in both hemispheres. Bottom left shows the local time difference of the open-closed boundary in the Northern and Southern Hemisphere. Solid lines are used for Northern Hemisphere conditions and dashed lines the Southern Hemisphere. The black line shows the dawn-dusk differences and red the noon-midnight differences. Bottom right shows the hemispheric latitude difference (summer-winter) of the open-close field line boundary in the noon, midnight, dawn, and dusk sectors as a function of the clock angle.

sector. The summer polar cap boundary is $12^{\circ}$ more poleward than the winter when the clock angle $=0^{\circ}$, then decrease to zero when the clock angle $=65^{\circ}$.

\section{Interpretation of the results}

\subsection{Time delay}

The model shows that the ionosphere reconfiguration time is about $10-20 \mathrm{~min}$ after the IMF encounters the magnetopause. This is quite comparable to previous observation results that for the development of the FACs from the magnetopause to the ionosphere an average delay of 15-22 min has 
been considered (Clauer and Friis-Christensen, 1988; Vennerstrom et al., 2002; Kabin et al., 2003). The model results also indicate that it takes a little longer for the south (i.e. summer) than the north (i.e. winter) hemisphere to complete the transition. The cause accounts for this hemispheric difference might be the deviation of the magnetic dipole from the GSM $Z$ axis.

\subsection{FACs density and location}

This simulation study gives a detailed configuration of NBZ and DPY FACs, which are quite comparable to previous observations. The dominant NBZ and R1 FACs increase in intensity as the clock angle increases, which is consistent with observations that the NBZ FACs are greatly enhanced when IMF $B_{y}$ becomes nonzero (Potemra et al., 1984). The model NBZ and R1 FACs are in general less than $0.2 \mu \mathrm{A} / \mathrm{m}^{2}$, which is lower than the observed quiet value $\left(\sim 0.5 \mu \mathrm{A} / \mathrm{m}^{2}\right)$ (e.g. Wang et al., 2005). The underestimation of the ionospheric current densities has been reported previously, which is due to the low resolution of the model (Ridley et al., 2001; Wang et al., 2008b). The summer NBZ and R1 FACs are larger in intensity than the winter, which is consistent with observations and has been explained by either the seasonal effects in ionospheric conductivity (Ridley et al., 2004) or the dipole tilt angle favoring more reconnection between the IMF and the summer hemisphere than the winter hemisphere (Zanetti et al., 1982). Future work will use the model to differentiate the relative importance of these two effects. The summer/winter differences of the NBZ and R1 FACs are 1.5 1.8 and $1 \sim 1.5$, respectively, which are comparable to previous statistical results that the difference between the summer FACs and winter FACs is around 1.5 2 (e.g. Wang et al., 2005). The summer cusp FACs are centered at higher latitudes than the winter. Previous studies have suggested that the cusp moves about $1^{\circ}$ poleward for each $14^{\circ}$ increase in the dipole tilt angle (Zhou et al., 1999). Wang et al. (2005) also found that the dayside FACs are located at higher latitude in daylight than in darkness.

\subsection{FACs source region}

As we have addressed in the introduction, there are a lot of disputes about whether the NBZ and DPY FACs originate on open or closed field lines. Our model results show that NBZ FACs originate on both closed and open field lines, which is consistent with previous model results (e.g. Vennerstrom et al., 2005). In addition, the origins of DPY FACs exhibit hemispheric asymmetry. The midday R1 FACs in the winter (i.e. north) hemisphere are on closed field lines while those in the summer (i.e. south) hemisphere are on both open and closed field lines. A small part of R0 FACs are on closed field lines in the winter hemisphere, while all the R0 FACs are on open field lines in the summer hemisphere. This hemispheric discrepancy has never been addressed before.
Determining the source region for the FACs will help understand the physical processes that are associated with the excitation of the current systems. Therefore, Fig. 8 shows color coded FACs strength in the magnetosphere in the noonmidnight meridian plane together with the streamlines of magnetic field connecting to the ionosphere. Positive values (red) denote FACs flowing parallel to the magnetic field and negative (blue) denotes antiparallel FACs. The left panel is for purely northward IMF and right for purely duskward IMF. In the left panel of Fig. 8, the upward NBZ FACs in both hemispheres can be clearly distinguished. The upward NBZ FACs (blue) in the Northern Hemisphere map magnetically to field lines in both the tail lobe and LLBL region of the magnetosphere, that is, both on open and closed field lines. In the Southern Hemisphere, the upward NBZ FACs (red) map to the magnetic lobe regions overdraping on the dayside of the magnetosphere and also to the plasma sheet on the nightside. The shear and rotation of these field lines are the source of the NBZ FACs, which is consistent with previous results (Iijima et al., 1984; Vennerstrom et al., 2005). In the right panel the midday R1 and R0 FACs are shown clearly in both hemispheres. In the Northern Hemisphere, the upward midday R0 FACs (blue) are located on both open and closed field lines, while the downward midday R1 FACs (red) are located on closed field lines on the dayside of the magnetosphere. In the Southern Hemisphere, the downward midday R0 FACs (blue) are located on open field lines draping tailward while the upward midday R1 FACs (red) are located on both open and closed field lines on the dayside of the magnetosphere. The southern open field lines shift duskward and the northern open field lines shift dawnward in accordance to the IMF direction.

Since the dominant process responsible for R1 FACs is the field-aligned vorticity, and that of R2 FACs is the pressure gradient (Sato and Iijima, 1979; Ogino et al., 1986), in Fig. 9, we have plotted the plasma pressure and field-aligned vorticity in the equatorial plane $(\mathrm{Z}=0)$ when the clock angle $=0^{\circ}$ and $90^{\circ}$. The field-aligned vorticity is defined as $(\nabla \times \boldsymbol{v}) \cdot \boldsymbol{B} /|B|, \boldsymbol{v}$ is the convection velocity, $\boldsymbol{B}$ is the magnetic field. Under northward IMF the strong pressure can be found on the dayside at a distance $10-15 R_{E}$, which is associated with the dayside cusp. Under duskward IMF another strong pressure appears on the nightside at $\mathrm{X}=-5 R_{E}$ with the center shifts towards premidnight. When mapping the pressure into the ionosphere, it centers around $65^{\circ}$ MLat, which corrsponds well to R2 FACs locations. During northward IMF ( $t=00: 00 \mathrm{UT}$ ), there are two groups of strong vorticities located symmetrically on the dawn and duskside, which are associated with the dawn and dusk R1 currents. During duskward IMF (03:00 UT), the vorticity become more concentrated while the centers do not change too much in locations, which is consistent with the fact that the peak R1 FACs in both hemispheres do not change significantly in locations (see Fig. 6). 

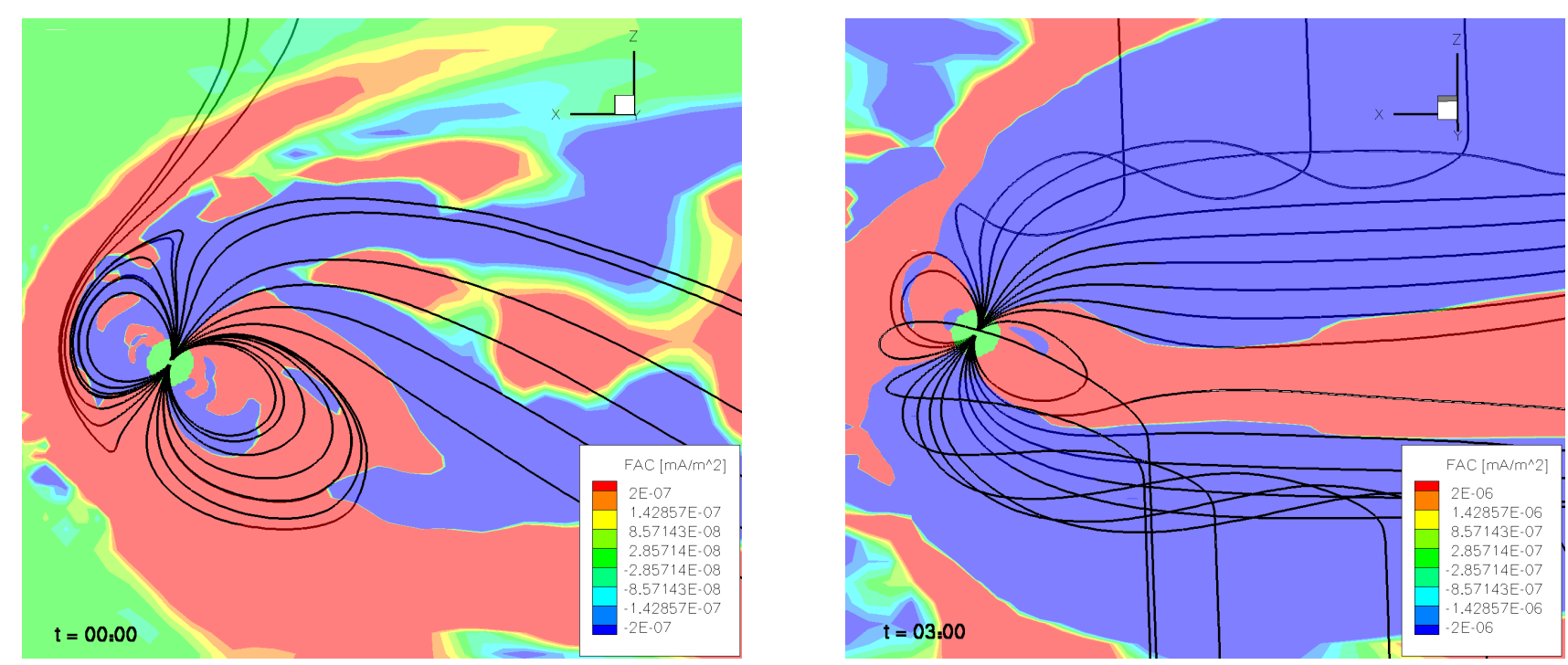

Fig. 8. Field line topology in the noon and midnight local time sectors at $5^{\circ}$ MLat intervals in the magnetosphere at 00:00 UT and 03:00 UT. The background color coding shows the field-aligned current densities $\left(\mathrm{mA} / \mathrm{m}^{2}\right)$ in the noon-midnight meridian plane. Positive (red) denotes parallel to the magnetic field and negative (blue) antiparallel currents.

\subsection{Magnetic reconnection}

The simulation study shows the inherent relationship between NBZ and DPY FACs. It shows that NBZ FACs can not evolve into DPY FACs in the Northern (e.g. winter) Hemisphere while it can evolve into DPY FACs in the Southern (e.g. summer) Hemisphere. This hemispheric discrepancy has never been addressed in the literature. Previous studies (e.g. Fedder and Lyon, 1995; Vennerstrom et al., 2002; Vennerstrom et al., 2005) have shown that NBZ FACs can evolve into DPY FACs during equinox seasons, but no explicit explanations have been given. We believe, however, it is associated with the place where the magnetospheric merging occurs. The site of magnetic reconnection between the IMF and the dayside magnetosphere is dependent on the orientation of the IMF (Dungey, 1963). Due to the dipole tilt, the high-latitude reconnection shows a strongly interhemispheric asymmetry, favoring the summer hemisphere (Crooker, 1992).

Two reconnection sites can be identified in the left panel of Fig. 8, by those kinked field lines in both polar regions. This reconnection topology is quite similar to the merging pattern in Fig. 1b of Crooker (1992). Due to the dipole tilt, the northward IMF merges with a closed magnetic field line in the Southern Hemisphere, forming open field lines in each hemisphere. The open field lines from the Southern Hemisphere are sharply bent forward while those from the Northern Hemisphere are overdraped tailward. The magnetopause merging site lies on the closed field lines on the nightside rather than on the dayside because the tail lobe drapes over the dayside rather than the nightside (Crooker,
1992). The open field lines in both hemispheres move together with the solar wind towards the magnetotail. Some time later the overdraped field lines from the summer (e.g. south) hemisphere reconnect with previously opened field lines from the winter (i.e. north) hemisphere on the dayside, forming closed field lines on the dayside and completely detached field lines. The magnetopause reconnection site lies on closed field lines on the dayside rather than on the nightside because the tail lobe drapes over the nightside rather than the dayside (Crooker, 1992). The reconnection process at the two cusps does not take place on the same flux tube and the reconnection rates are not the same at the two cusps with the southern being larger than the northern. The reason is that the dipole tilt angle breaks the north-south symmetry. This is consistent with previous observations that the enhanced emission intensity of the aurora seems to occur predominantly when the hemisphere is tilted more towards the sun. Since the aurora during the northward IMF is a signature of high-latitude reconnection, this means that the enhanced reconnection occurs in the favored hemisphere (Øieroset et al., 1997). We term the merging between the IMF and the closed field line of the earth as magnetic merging, $E m$ while the merging between the open field lines of the earth as magnetic reconnection, $E r$, in the following.

As the IMF rotates duskward, the merging site of $E m$ will shift towards the dawnside in the Southern Hemisphere and the reconnection site of $E r$ to the duskside in the Northern Hemisphere. Figure 10 shows the merging site of $E m$ as IMF changes in direction. The terrestrial closed field lines are shown with the reconnecting IMF and closed field line color indicated. The upper row is viewing from the dawnside and 
the bottom row from the sun. The merging site can be found on the nightside as seen from the upper panels, and shift towards dawn as IMF rotates from northward to duskward as seen from left to right at the bottom panels.

The counterclockwise rotation of NBZ FACs can be explained by the variations of merging and reconnection sites with the IMF rotation. For simplicity, Fig. 11 depicts schematically a cartoon of the ionospheric NBZ FACs (blue ovals) and sunward convection associated with the mapping $E m$ and $E r$. Left is in the northern polar cap and right in the southern polar cap. The Em can map on the nightside into the summer (south) ionosphere, not into the winter (north) ionosphere because of the long distance to the north polar ionosphere (Crooker, 1992). As seen in the top right panel of Fig. 11, the $E m$ drives sunward convection on the nightside in the south polar cap. The two NBZ FACs are quite symmetric with respect to the noon-midnight meridian. The reconnection electric field $E r$ maps to the dayside in the winter (north) polar cap, as shown in the top left panel, pulling the reverse convection and making NBZ FACs symmetric with respect to the noon-midnight meridian.

When the IMF rotates from northward to duskward, the merging sites shift to the dawnside in the Southern Hemisphere and the reconnection site to the duskside in the Northern Hemisphere. Therefore, the electric fields map to postmidnight in the summer hemisphere and postnoon in the winter hemisphere, as seen at the bottom two panels in Fig. 11. These make the plasma drift in sunward-duskward direction in both the summer and winter hemispheres. In addition, the two NBZ FACs rotate counterclockwise in both hemispheres with one of them shrinking in size and the other dominating most of the dayside (nightside) of the north (south) polar cap. Thus, in the summer (i.e. south) hemisphere, both NBZ FACs can evolve into DPY FACs (i.e. the midday R0 and R1 FACs) in the midday sector. But in the winter hemisphere, the shrinking NBZ FACs can not evolve into the midday R1 FACs since it shifts towards nightside of the polar cap.

If the dipole tilt is zero (i.e. around equinox), as investigated in previous studies (e.g. Feldman et al., 1995; Vennerstrom et al., 2002; Vennerstrom et al., 2005), the IMF will merge with the Earth's magnetic field in both hemispheres simultaneously and symmetrically, and the merging electric field, Em, will be mapped to the nightside in both hemispheres. When a duskward IMF is introduced, the merging sites will move to the dusk (dawn) sector in the Northern (Southern) Hemisphere, thus making the two NBZ FACs rotate clockwise in the Northern Hemisphere and counterclockwise in the Southern Hemisphere. This configuration causes the NBZ FACs to rotate into the DPY FACs in both hemispheres.

Finally we may conclude that the dipole tilt has great effect on the evolution of FACs patterns by influencing the merging sites in the magnetosphere. Nearly all aspects of the topology can be achieved if the dipole tilt is replaced by a superposition of a finite IMF $B_{x}$ component (Lyons, 1985). Both
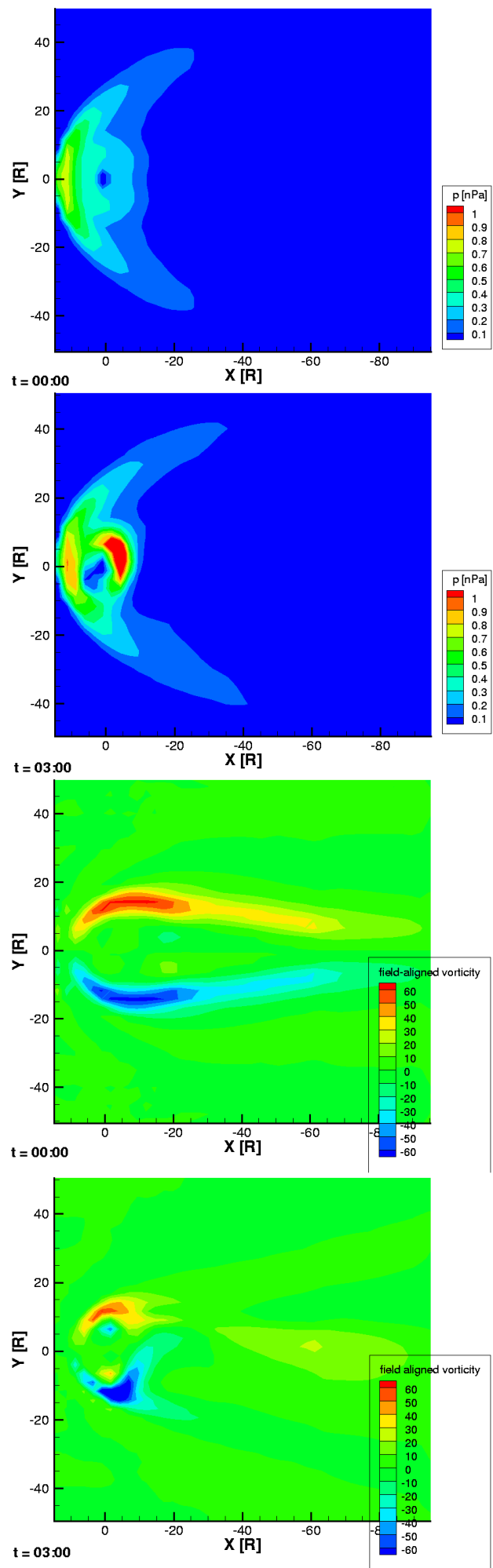

Fig. 9. Cross sectional panels in the $\mathrm{Z}=0$ plane of the plasma pressure (upper panel) and field-aligned vorticity (bottom panel). The left is at 00:00 UT and the right at 03:00 UT. 


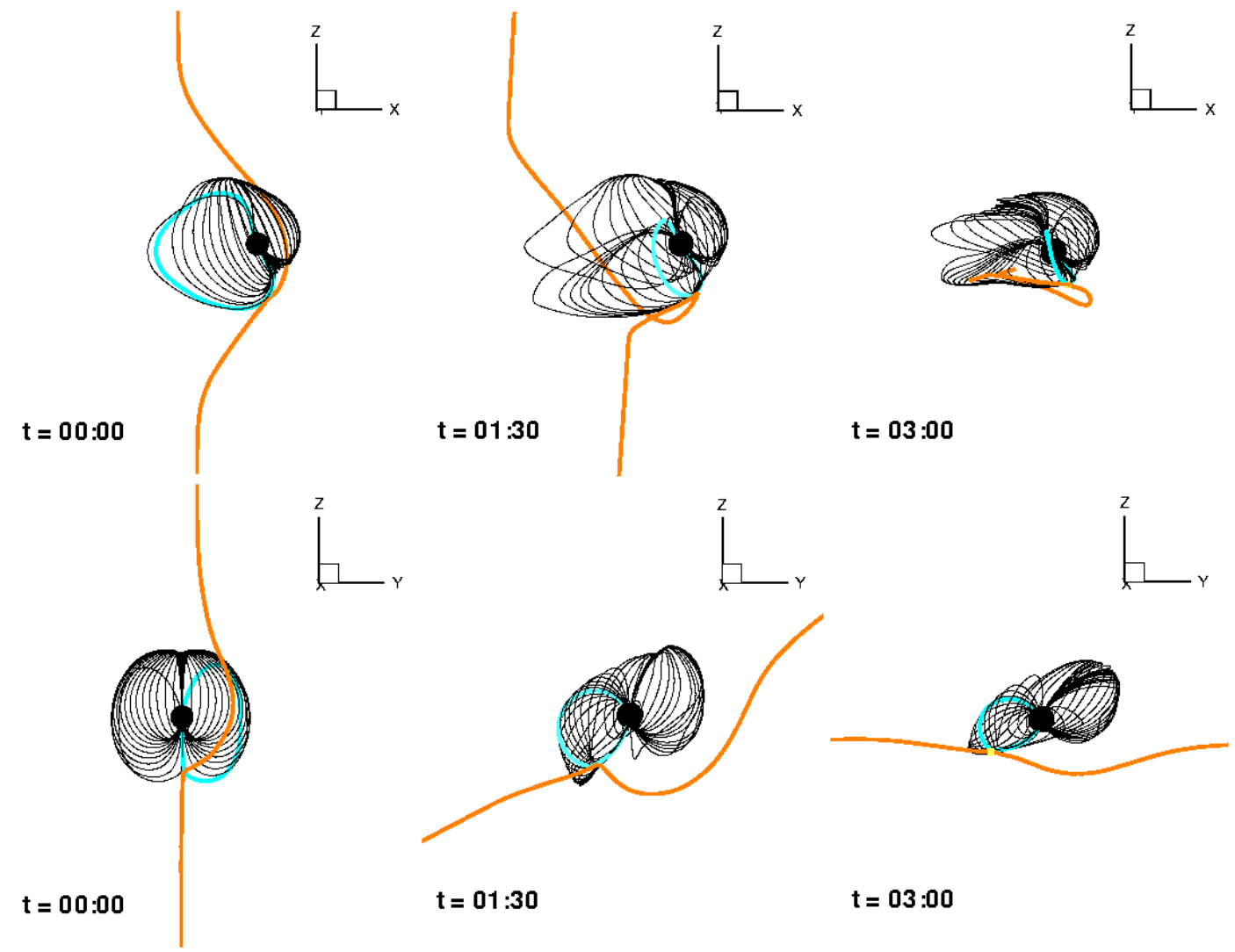

Fig. 10. The site of merging between the IMF (yellow line) and the earth's magnetic field (blue line) for three UT times. Only the closed field lines of the Earth are shown. The upper row is seen from the dawnside and the bottom from the sun.

positive IMF $B_{x}$ and negative dipole tilt favor more merging between the IMF and the south magnetosphere (Crooker, 1992).

\subsection{Polar cap boundary and plasma sheet}

As the IMF rotates from northward to duskward, both polar caps grow in size, with the northern polar cap displacing towards the dawnside and the southern polar cap moving towards the duskside, exhibiting a local time and hemispheric asymmetry. The hemispheric difference of the open/closed polar cap boundary on the nightside can reach $12^{\circ}$, while previous studies reported that changing the dipole tilt angle by $35^{\circ}$ results only in $1-2^{\circ}$ latitude change in the open/closed boundary (Kabin et al., 2004). However, their studies have not considered events under the northward IMF condition. When the clock angle $>65^{\circ}$, the midnight polar caps are at the same latitudes in the Northern as in the Southern Hemisphere, which deviates from previous studies stating that the summer polar cap in the midnight is located at higher latitude than the winter (Kabin et al., 2004). The summer polar cap around noon is in general located at lower latitude than the winter polar cap, which is consistent with previous results showing that the winter open/closed polar cap boundary is located at higher latitudes than in the summer on the dayside (Kabin et al., 2004).

When the IMF is northward, the summer polar cap is closed on the nightside while the winter polar cap is open. In the summer hemisphere, the polar cap on the dawnside shift poleward when the clock angle is less than $10^{\circ}$. It is known that the mapping from the tail plasma sheet to the ionosphere gives qualitatively the form of the auroral oval (e.g. Kullen and Janhunen, 2004; Nishida et al., 1998). Therefore, the further poleward displacement of the open/closed polar cap boundary in one oval is expected to be caused by a twist of the tail plasma sheet. The twisted plasma sheet is expected to be shaped by the twist of the northern and the southern open field lines. To understand how the twist of the open field lines causes the twisted plasma sheet, Fig. 12 shows the plasma pressure within cross session of the tail at $\mathrm{X}=$ $-10 R_{E}$, as well as the newly created open field lines due to the reconnection with the IMF in both hemispheres. Red lines denote those connect to the Northern Hemisphere and black to the Southern Hemisphere. The open field lines cross the $\mathrm{X}=-10 R_{E}$ plane three times. The end part of the open field lines is in the IMF direction, as seen from those field lines sticking out of the Y-Z plane at the top and bottom. The blue regions (low plasma pressure) in both hemispheres 

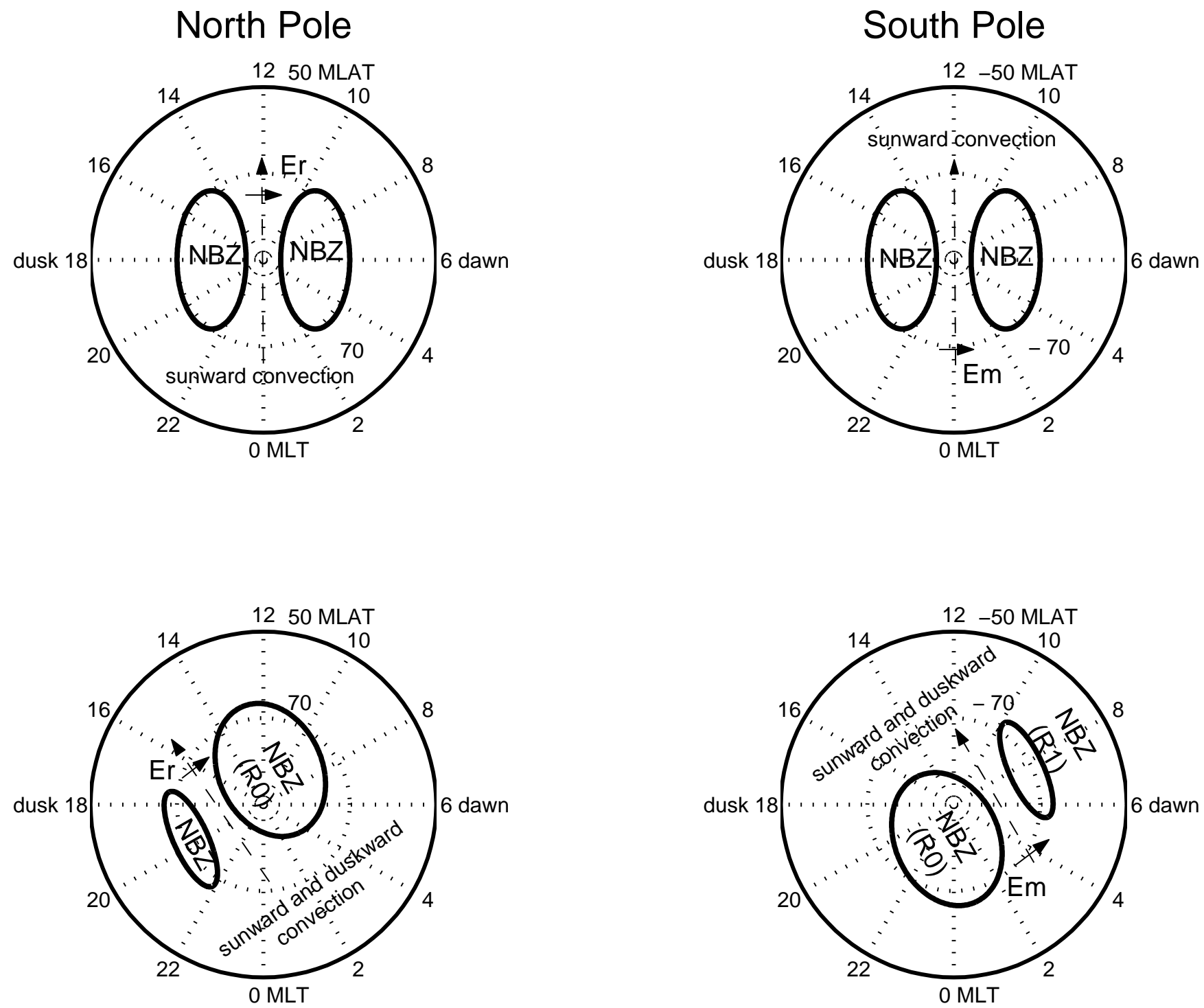

Fig. 11. NBZ FACs, convection velocity associated with the mapped merging $(E m)$ and reconnected electric field (Er). The top two panels are for purely northward IMF, and the bottom two panels are for northward and duskward IMF. The left column is in the Northern Hemisphere and the right is in the Southern Hemisphere. The two blue ovals mark the area of NBZ FACs. The dashed arrow line denotes the convection velocity and the real arrow line denotes the merging and reconnection electric field.

indicate the lobes while the red regions (high plasma pressure) in between the lobe regions indicates the plasma sheet.

Under northward IMF, newly created opened field lines are symmetric with respect to the noon-midnight meridian $(\mathrm{Z}$ axis), but asymmetric with respect to the dawn-dusk meridian ( $\mathrm{Y}$ axis). The plasma sheet extends more to the south lobe region. This makes the closed polar cap on the nightside in the south pole. The closed polar cap on the nightside may be associated with the theta aurora (Frank et al., 1982; Ogino et al., 1985; Eriksson et al., 2005). Previous studies also show that theta aurora tends to occur only in the summer hemisphere (Østgaard et al., 2003).
At 00:30 and 01:00 UT, the southern lobe on the dawnside disappear due to the changing open field lines topology. The dawnside plasma sheet in the Southern Hemisphere expands more to the south lobe region. This is consistent with a poleward retreat of the southern polar cap boundary at dawn. This is also consistent with previous observations that the southern theta aurora shifts dawnward as IMF rotates duskward (Ogino et al., 1985). As the duskward component of the IMF increases and the northward component of the IMF decreases, open field lines originating from the Southern Hemisphere (black lines) appear on the dawnside, thus, the southern lobe at dawn expands in Z-direction. The 

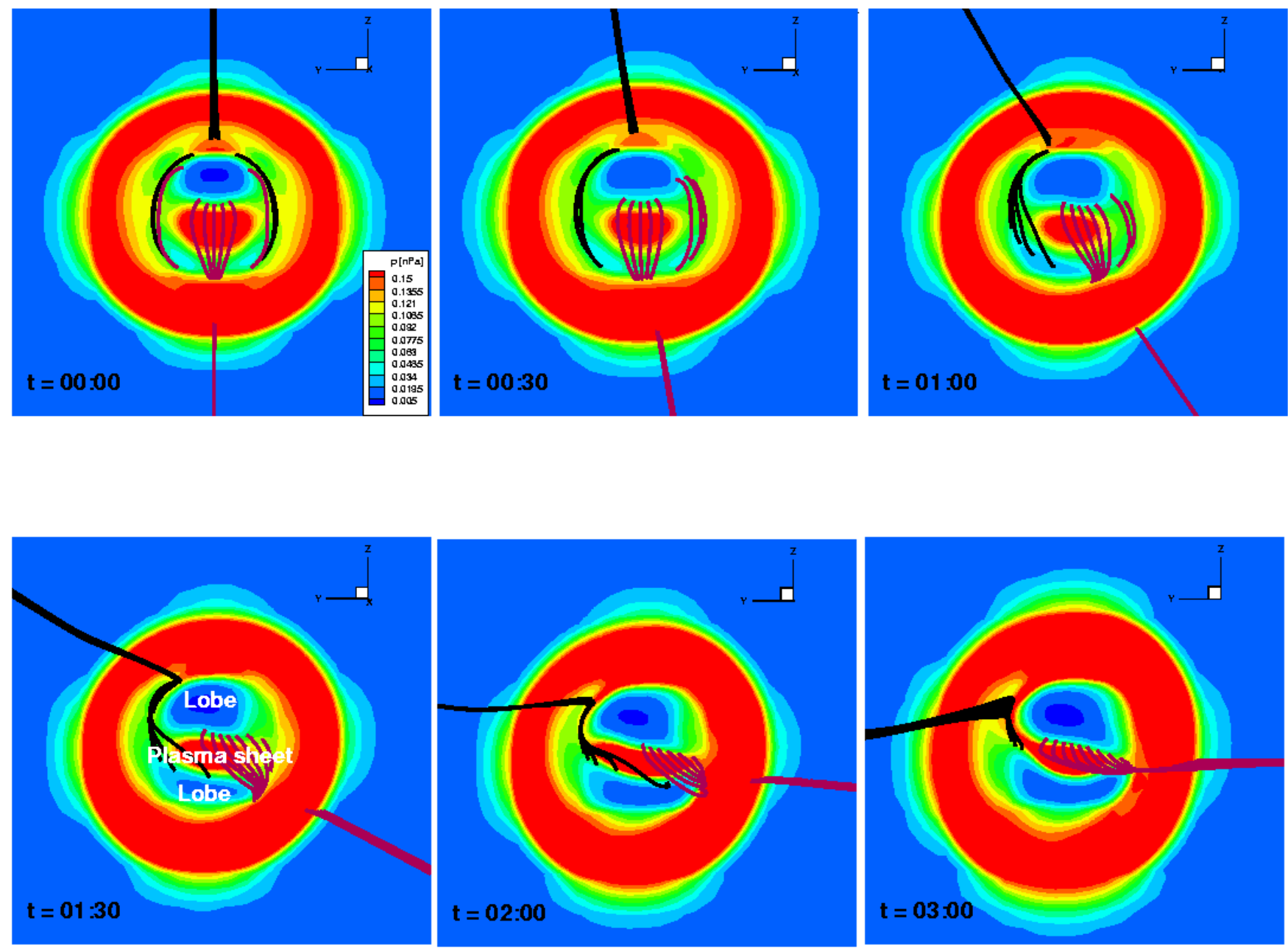

Fig. 12. Cross sectional panel in the Y-Z plane of the plasma pressure at $x=-10 R_{E}$. The newly opened field lines are also shown. Black line indicates those that connect to the Southern Hemisphere and red to the Northern Hemisphere.

plasma sheet changes shape in accordance with the changing open field lines topology. The plasma sheet shrinks in Z-direction, expand in $\mathrm{Y}$ direction. This is consistent with the displacement of the northern polar cap toward dawn and the southern polar cap toward dusk. The plasma sheet also expands gradually in the radial direction when IMF rotates from northward to duskward (not shown). Previous simulations also showed that the length of the magnetotail become longer as $B_{z}$ varies from a finite positive value to zero (e.g. Usadi et al., 1993; Song et al., 1999).

\section{Summary}

This study examines the field-aligned current patterns for a configuration when the IMF rotates from northward toward duskward with nonzero dipole tilt. The dipole tilt is shown to have an important effect on the evolution of the FACs pattern in both hemispheres. As IMF rotates from northward to duskward, the NBZ FACs shift both counterclockwise in the summer (i.e. south) and winter (i.e. north) hemispheres. However, in the winter hemisphere the dawnward NBZ FACs become dominate in the polar cap region on the dayside, thus prohibiting the duskward NBZ FACs from evolving into the midday R1 FACs. The midday R1 FACs seems to be an intrusion of dawnside R1 FACs. In the summer hemisphere the duskside NBZ FACs become dominate in the polar cap on the nightside and the dawnside NBZ FACs can evolve into the midday R1 FACs after the counterclockwise rotation. The hemispheric asymmetry is caused by the dipole tilt, which favor more merging between the IMF and the summer hemisphere. The merging electric field maps to the nightside in the summer hemisphere and the reconnection electric field maps to the dayside in the winter hemisphere. The differences in the mapping sites make the NBZ FACs evolve differently in the Northern and Southern Hemispheres, thus prohibiting the winter NBZ FACs from evolving into DPY FACs. 
When mapping the NBZ and DPY FACs into the magnetosphere, it is shown that the NBZ currents are located on both open and closed field lines, irrespective of the IMF rotation. The midday R1 FACs and some part of R0 FACs are on closed field lines in the Northern (winter) Hemisphere, while some part of the midday R1 FACs and all the R0 FACs are on open field lines in the Southern (summer) Hemisphere.

As the IMF rotates from northward to duslward, both polar caps grow in size, with the northern polar cap displacing towards the dawnside and the southern polar cap moving towards the duskside, exhibiting a local time and hemispheric asymmetry. The polar cap boundary tends to move equatorward as IMF rotates from northward to duskward, except in the Southern Hemisphere, there is a poleward shift of the polar cap on the dawnside when the clock angle $<10^{\circ}$. When the IMF is purely northward, the noon-midnight asymmetry dominates the dawn-dusk asymmetry, which is more obvious in the summer hemisphere. As IMF $B_{y}$ increases in intensity, the dawn-dusk asymmetry increases while the noon-midnight asymmetry decreases. And the changes occur quicker in the summer than in the winter hemisphere. During purely northward IMF, the hemispheric asymmetry is most dramatic on the nightside due to the effect of the dipole tilt. Under these conditions, the hemispheric difference of the open /closed field line boundary reaches $12^{\circ}$. As the clock angle $>65^{\circ}$, the midnight polar caps attain the same latitudes in the Northern and Southern Hemispheres. The twist of the tail plasma sheet in accordance with the open field lines topology can account for the changes of the openclosed boundaries in both hemispheres.

In summary, we have used the SWMF model as a tool to simulate the detailed configuration of NBZ and DPY FACs under varying IMF orientations with nonzero dipole tilt. The model results are almost consistent with previous observations and can be regarded as a validation effort to the model. The model indicates that the dipole tilt has great effects on the relationship between NBZ and DPY FACs. The physical mechanism of the phenomena has also been discussed.

Acknowledgements. We thank the Center of Space Environment Modeling (CSEM) at University of Michigan for developing the Space Weather Modeling Framework (SWMF) model, which make this study possible. We are grateful to D. L. De Zeeuw at University of Michigan for helpful discussion. This work is supported by the NASA research grant F010639, NSF grant ATM 0639336, and by National Nature Science Foundation of China (No. 40604017).

Topical Editor M. Pinnock thanks S. Petrinec and another anonymous referee for their help in evaluating this paper.

\section{References}

Burke, W. J., Kelley, M. C., Sagalyn, R. C., Smiddy, M., and Lai, S. T.: Polar cap electric field structures with a northward interplanetary magnetic field, Geophys. Res. Lett., 6, 21-24, 1979.

Clauer, C. R. and Friis-Christensen, E.: High-latitude dayside electric fields and currents during strong northward interplanetary magnetic field - Observations and model simulation, J. Geophys. Res., 93, 2749-2757, 1988.

Crooker, N. U.: Mapping the merging potential from the magnetopause to the ionosphere through the dayside cusp, J. Geophys. Res., 93, 7338-7344, 1988.

Crooker, N. U.: Reverse convection, J. Geophys. Res., 97, 1936319372, 1992.

Crooker, N. U., Luhmann, J. G., Spreiter, J. R., and Stahara, S. S.: Magnetopause merging site asymmetries, J. Geophys. Res., 90, 341-346, 1985.

Crooker, N. U., Lyon, J. G., and Fedder, J. A.: MHD model merging with IMF $B_{y}$ : Lobe cells, sunward polar cap convection, and overdraped lobes, J. Geophys. Res., 103, 9143-9152, doi: 10.1029/97JA03393, 1998.

De Zeeuw, D. L., Sazykin, S., Wolf, R. A., Gombosi, T. I., Ridley, A. J., and Tóth, G.: Coupling of a global MHD code and an inner magnetospheric model: Initial results, J. Geophys. Res., 109, A12219, doi:10.1029/2003JA010366, 2004.

Dungey, J. W.: The structure of the exosphere or adventures in velocity space, in: Geophysics, The Earth's Environment, edited by DeWitt, C., Hieblot, J., and Lebeau, A., Gordon and Breach, New York, 1963.

Eriksson, S., Baker, J. B. H., Petrinec, S. M., Wang, H., Rich, F. J., Kuznetsova, M., Dunlop, M. W., Rème, H., Greenwald, R. A., Frey, H. U., Lühr, H., Ergun, R. E., Balogh, A., and Carlson, C. W.: On the generation of enhanced sunward convection and transpolar aurora in the high-latitude ionosphere by magnetic merging, J. Geophys. Res., 110, A11218, doi: 10.1029/2005JA011149, 2005.

Erlandson, R. R., Zanetti, L. J., Potemra, T. A., Bythrow, P. F., and Lundin, R.: IMF By dependence of region 1 Birkeland currents near noon, J. Geophys. Res., 93, 9804-9814, 1988.

Fedder, J. A. and Lyon, J. G.: The Earth's magnetosphere is 165 $\mathrm{R}$ (sub E) long: Self-consistent currents, convection, magnetospheric structure, and processes for northward interplanetary magnetic field, J. Geophys. Res., 100, 3623-3635, 1995.

Fedder, J. A., Slinker, S. P., Lyon, J. G., Russell, C. T., Fenrich, F. R., and Luhmann, J. G.: A first comparison of POLAR magnetic field measurements and magnetohydrodynamic simulation results for field-aligned currents, Geophys. Res. Lett., 24, 24912494, doi:10.1029/97GL02608, 1997.

Feldman, W. C., Hones, E. W., Barraclough, B. L., Reeves, G. D., Belian, R. D., Clayton, T. E., Lee, P., Lepping, R. P., Trombka, J. I., Starr, R., Moersch, J., Squyres, S. W., and Rich, F. J.: Possible conjugate reconnection at the high-latitude magnetopause, J. Geophys. Res., 100, 14 913-14 924, doi:10.1029/95JA01217, 1995.

Frank, L. A., Craven, J. D., Burch, J. L., and Winningham, J. D.: Polar views of the earth's aurora with Dynamics Explorer, Geophys. Res. Lett., 9, 1001-1004, 1982.

Friis-Christensen, E., Kamide, Y., Richmond, A. D., and Matsushita, S.: Interplanetary magnetic field control of high-latitude electric fields and currents determined from Greenland magnetometer data, J. Geophys. Res., 90, 1325-1338, 1985.

Iijima, T. and Potemra, T.: Field-aligned currents in the dayside cusp observed by Triad, J. Geophys. Res., 81, 5971-5979, 1976.

Iijima, T. and Potemra, T.: The relationship between interplanetary quantities and Birkeland currnet densities, Geophys. Res. Lett., $9,442-445,1982$. 
Iijima, T. and Shibaji, T.: Global characteristics of northward IMFassociated (NBZ) field-aligned currents, J. Geophys. Res., 92, 2408-2424, 1987.

Iijima, T., Potemra, T. A., Zanetti, L. J., and Bythrow, P. F.: Large-scale Birke-land currents in the dayside polar region during strongly northward IMF: Anew Birkeland current system, J. Geophys. Res., 89, 7441-7452, 1984.

Kabin, K., Rankin, R., Marchand, R., Gombosi, T. I., Clauer, C. R., Ridley, A. J., Papitashvili, V. O., and DeZeeuw, D. L.: Dynamic response of Earth's magnetosphere to $B_{y}$ reversals, J. Geophys. Res., 108, A31132, doi:10.1029/2002JA009480, 2003.

Kabin, K., Rankin, R., Rostoker, G., Marchand, R., Rae, I. J., Ridley, A. J., Gombosi, T. I., Clauer, C. R., and DeZeeuw, D. L.: Open-closed field line boundary position: A parametric study using an MHD model, J. Geophys. Res., 109, 5222, doi: 10.1029/2003JA010168, 2004.

Kullen, A. and Janhunen, P.: Relation of polar auroral arcs to magnetotail twisting and IMF rotation: a systematic MHD simulation study, Ann. Geophys., 22, 951-970, 2004,

http://www.ann-geophys.net/22/951/2004/.

Le, G., Lu, G., Strangeway, R. J., and Pfaff, R. F.: Strong interplanetary magnetic field $\mathrm{B}_{y}$-related plasma convection in the ionosphere and cusp field-aligned currents under northward interplanetary magnetic field conditions, J. Geophys. Res., 107, A121477, doi:10.1029/2001JA007546, 2002.

Lockwood, M. and Moen, J.: Reconfiguration and closure of lobe flux by reconnection during northward IMF: possible evidence for signatures in cusp/cleft auroral emissions, Ann. Geophys., 17, 996-1011, 1999,

http://www.ann-geophys.net/17/996/1999/.

Lyons, L. R.: A simple model for polar cap convection patterns and generation of theta auroras, J. Geophys. Res., 90, 1561-1567, 1985.

McDiarmid, I. B., Burrows, J. R., and Wilson, M. D.: Large-scale magnetic field perturbations and particle measurements at 1400 km on the dayside, J. Geophys. Res., 84, 1431-1441, 1979.

Mei, Y., Crooker, N. U., and Siscoe, G. L.: Cusp current modeling: A systematic approach, J. Geophys. Res., 99, 4027-4038, 1994.

Nishida, A., Mukai, T., Yamamoto, T., Kokubun, S., and Maezawa, K.: A unified model of the magnetotail convection in geomagnetically quiet and active times, J. Geophys. Res., 103, 4409-4418, doi:10.1029/97JA01617, 1998.

Ogino, T., Walker, R. J., Ashour-Abdalla, M., and Dawson, J. M.: An MHD simulation of By-dependent magnetospheric convection and field-aligned currents during northward IMF, J. Geophys. Res., 90, 10 835-10 842, 1985.

Ogino, T., Walker, R. J., Ashour-Abdalla, M., and Dawson, J. M.: An MHD simulation of the effects of the interplanetary magnetic field By component on the interaction of the solar wind with the earth's magnetosphere during southward interplanetary magnetic field, J. Geophys. Res., 91, 10 029-10 045, 1986.

Øieroset, M., Sandholt, P. E., Denig, W. F., and Cowley, S. W. H.: Northward interplanetary magnetic field cusp aurora and highlatitude magnetopause reconnection, J. Geophys. Res., 102, 11 349-11362, doi:10.1029/97JA00559, 1997.

Østgaard, N., Mende, S. B., Frey, H. U., Frank, L. A., and Sigwarth, J. B.: Observations of non-conjugate theta aurora, Geophys. Res. Lett., 30(21), 2125, doi:10.1029/2003GL017914, 2003.

Park, K. S., Ogino, T., and Walker, R. J.: On the importance of antiparallel reconnection when the dipole tilt and IMF $\mathrm{B}_{y}$ are nonzero, J. Geophys. Res., 111, A05202, doi:10.1029/ 2004JA010972, 2006.

Potemra, T. A., Zanetti, L. J., Bythrow, P. F., Lui, A. T., and Iijima, T.: By dependent convection during northward interplanterary magnetic field, J. Geophys. Res., 89, 9753-9760, 1984.

Potemra, T. A., Zanetti, L. J., Erlandson, R. E., Bythrow, P. F., Gustafsson, G., and Acuna, M. H.: Observations of large-scale Birkeland currents with Viking, Geophys. Res. Lett., 14, 419422, 1987.

Powell, K. G., Roe, P. L., Linde, T. J., Gombosi, T. I., and Zeeuw, D. L. D.: A solution-adaptive upwind scheme for ideal magnetohydrodynamics, J. Comp. Phys., 154, 284-309, 1999.

Reiff, P. H. and Burch, J. L.: IMF $\mathrm{B}_{y}$-dependent plasma flow and birkland currents in the dayside magnetosphere: 2. A global model for northward and southward IMF, J. Geophys. Res., 90, 1595-1609, 1985.

Ridley, A. J., De Zeeuw, D. L., Gombosi, T. I., and Powell, K. G.: Using steady state MHD results to predict the global state of the magnetosphere ionosphere system, J. Geophys. Res., 106, 30 067-30 076, 2001.

Ridley, A. J., Gombosi, T. I., and DeZeeuw, D. L.: Ionospheric control of the magnetosphere: Conductance, Ann. Geophys., 22, 567-584, 2004, http://www.ann-geophys.net/22/567/2004/.

Sato, T. and Iijima, T.: Primary sources of field-aligned currents, Space Science Review, 24, 347-366, 1979.

Song, P., Zeeuw, D. L. D., Gombosi, T. I., Groth, C. P. T., and Powell, K. G.: A numerical study of solar wind-magnetosphere interaction for northward interplanetary magnetic field, J. Geophys. Res., 104, 28 361-28 378, 1999.

Taguchi, S., Sugiura, M., Winningham, J. D., and Slavin, J. A.: Characterization of the IMF By-dependent field-aligned currents in the cleft region based on DE 2 observations, J. Geophys. Res., 98, 1393-1407, 1993.

Taguchi, S., Sugiura, M., Iyemori, T., Winningham, J. D., and Slavin, J. A.: By-controlled convection and field-aligned currents near midnight auroral oval for northward interplanetary magnetic field, J. Geophys. Res., 99, 6027-6044, 1994.

Tanaka, T.: Configuration of the magnetosphere-ionosphere convection system under northward IMF conditions with nonzero IMF $B_{y}$, J. Geophys. Res., 104, 14683-14 690, doi:10.1029/ 1999JA900077, 1999.

Toffoletto, F., Sazykin, S., Spiro, R., and Wolf, R.: Inner magnetospheric modeling with the Rice Convection Model, Space Sci. Rev., 107, 175-196, 2003.

Tóth, G., Sokolov, I. V., Gombosi, T. I., Chesney, D. R., Clauer, C. R., De Zeeuw, D. L., Hansen, K. C., Kane, K. J., Manchester, W. B., Oehmke, R. C., Powell, K. G., Ridley, A. J., Roussev, I. I., Stout, Q. F., Volberg, O., Wolf, R. A., Sazykin, S., Chan, A., Yu, B., and Kóta, J.: Space Weather Modeling Framework: A new tool for the space science community, J. Geophys. Res., 110, A12226, doi:10.1029/2005JA011126, 2005.

Tóth, G., Zeeuw, D., Gombosi, T. I., Manchester, W. B., Ridley, A. J., Sokolov, I. V., and Roussev, I. I.: Sun-to-thermosphere simulation of the 28-30 October 2003 storm with the Space Weather Modeling Framework, Space Weather, 5, S06003, doi:10.1029/2006SW000272, 2007.

Usadi, A., Kageyama, A., Watanabe, K., and Sato, T.: A global 
simulation of the magnetosphere with a long tail - Southward and northward interplanetary magnetic field, J. Geophys. Res., 98, 7503-7517, 1993.

Vennerstrom, S., Moretto, T., Olsen, N., Friis-Christensen, E., Stampe, A. M., and Watermann, J.: Field-aligned currents in the dayside cusp and polar cap region during northward IMF, J. Geophys. Res., 107, A81188, doi:10.1029/2001JA009162, 2002.

Vennerstrom, S., Moretto, T., Rastätter, L., and Raeder, J.: Fieldaligned currents during northward interplanetary magnetic field: Morphology and causes, J. Geophys. Res., 110, A06205, doi: 10.1029/2004JA010802, 2005.

Wang, H., Lühr, H., and Ma, S. Y.: Solar zenith angle and merging electric field control of field-aligned currents: A statistical study of the southern hemisphere, J. Geophys. Res., 110, A03306, doi:10.1029/2004JA010 530, 2005.

Wang, H., Lühr, H., Ridley, A. J., Ritter, P., and Yu, Y.: Storm time dynamics of auroral electrojets: CHAMP observation and the Space Weather Modeling Framework simulation, Ann. Geophys., 26, 555-570, 2008a,

http://www.ann-geophys.net/26/555/2008/.

Wang, H., Ridley, A. J., and Lühr, H.: Validation of the Space Weather Modeling Framework with CHAMP and DMSP satellite observations, Space Weather, 6, S03001, doi:10.1029/2007SW000355, 2008b.
Watanabe, M., Iijima, T., and Rich, F. J.: Synthesis models of dayside field-aligned currents for strong interplanetary magnetic field By, J. Geophys. Res., 101, 13 303-13 320, doi:10.1029/ 96JA00482, 1996.

Wilhjelm, J. E., Friis-Christensen, E., and Potemra, T. A.: The relationship between ionospheric and field-aligned currents in the dayside cusp, J. Geophys. Res., 83, 5586-5592, 1978.

Yamauchi, M., Lundin, R., and Woch, J.: The interplanetary magnetic field By effects on large-scale field-aligned currents near local noon - Contributions from cusp part and noncusp part, J. Geophys. Res., 98, 5761-5767, 1993.

Zanetti, L. J., Potemra, T. A., Doering, J. P., Lee, J. S., Fennell, J. F., and Hoffman, R. A.: Interplanetary magnetic field control of high-latitude activity on July 29, 1977, J. Geophys. Res., 87, 5963-5975, 1982.

Zhou, X. W., Russell, C. T., Le, G., Fuselier, S. A., and Scudder, J. D.: The polar cusp location and its dependence on dipole tilt, Geophys. Res. Lett., 26, 429-432, 1999. 